\title{
Estudios en neurociencias: aportes para la investigación en cultivo de células madre mesenquimales
}

Geraldine Zidae Salazar Vargas Laboratorio de Neurociencias. Universidad Peruana Cayetano Heredia. Lima, Perú

Víctor Manuel Neyra Chagua Laboratorio de Neurociencias. Universidad Peruana Cayetano Heredia. Lima, Perú Laboratorio de Histocompatibilidad y Biología Molecular, Hospital Nacional Cayetano Heredia. Lima, Perú

Christian Roberto Pitot Álvarez Laboratorio de Neurociencias. Universidad Peruana Cayetano Heredia. Lima. Perú

Ana María Muñoz Jáuregui Facultad de Ciencias de la Salud. Universidad San Ignacio de Loyola. Lima, Perú

Luis Ángel Aguilar Mendoza Facultad de Ciencias de la Salud. Universidad San Ignacio de Loyola. Lima. Perú.

Recibido: 17 de setiembre del 2017 Aceptado: 3 de febrero del 2018 doi: https://doi.org/10.26439/persona2018.n021.1993

La reparación de tejidos es uno de los grandes retos actuales en medicina regenerativa y las células madres mesenquimales MSC, son la respuesta a esta necesidad por las características multipotencial, inmunosupresoras, antiinflamatorias y efecto paracrino. En el presente trabajo, describimos la técnica de aislamiento enzimático y cultivo in vitro de MSC a partir de una muestra real de tejido adiposo. Ello responderá a la necesidad de un conjunto de herramientas necesarias en la práctica clínica de terapia por células madre, autotransplante y quirúrgicas en las diferentes especialidades médicas y en el campo de la investigación, como potencial herramienta para estudios de toxicidad y dosis letal media in vitro. Se señala la importancia que el tema puede tener para la psicología, la psiquiatría y la neurología.

Palabras clave: células madre / Medicina regenerativa / cultivos celulares 


\section{Neuroscience Studies: Contributions to Research in Mesenchymal Stem Cell Culture}

Tissue repair is one of the great current challenges in regenerative medicine and the mesenchymal stem cells MSCs are the answer to this need because of the multipotential, immunosuppressive, anti-inflammatory and paracrine effects. In the present work, we describe the technique of enzymatic isolation and in vitro culture of MSCs from a real sample of adipose tissue. This will respond to the need for a set of tools necessary in the clinical practice of therapy by stem cells, autotransplant and surgical in different medical specialties and in the field of research as a potential tool for studies of toxicity and in vitro medium lethal dose. It points out the importance that the topic can have for psychology, psychiatry and neurology. 


\section{INTRODUCCIÓN}

Está demostrado que las células madre mesenquimales (Mesenchymal Stem Cells: MSC) tienen una habilidad inherente para autorrenovarse, proliferar y diferenciarse hacia tejidos maduros dependiendo del microambiente que las rodea. Tales características, intrínsecas a todas las células mesenquimales (CM), las hacen muy atractivas para su uso en terapia celular y en medicina regenerativa. Originalmente se creía que estas células se encontraban exclusivamente en la médula ósea, donde residen los progenitores y precursores hematopoyéticos junto con otras células que proveen un soporte estructural para la hematopoyesis, como el estroma de la médula ósea; sin embargo, también se ha demostrado la presencia de estas células en el tejido graso (Zuk, Zhu y Ashjian, 2002; Zuk, 2010; Rastegar, Shenaq, Huang, 2010; Bertassoli et al., 2013; De Girolamo et al., 2013), páncreas, hígado, músculo esquelético, dermis, membrana sinovial, hueso trabecular, sangre del cordón umbilical, tejido pulmonar, pulpa dental y ligamento periodontal (Macías-Abraham, Del Valle Pérez, Hernández-Ramírez y Ballester-Santovenia, 2010). Con respecto a la cantidad de MSC, en médula ósea constituyen un aproximado de $0.0001 \%-0.01 \%$ de todas las células nucleadas de la médula ósea, a diferencia del tejido adiposo que contiene aproximadamente 100000 MSC por gramo de grasa, lo que constituye para el tejido adiposo una fuente abundante y de fácil obtención de MSC, para ingeniería de tejidos y aplicaciones en medicina regenerativa ( $\mathrm{Ra}$ et al., 2011).
A pesar de los grandes avances que se realizan en la actividad clínica, todavía no existe un acuerdo claro acerca de la nomenclatura utilizada para describir las células progenitoras del estroma del tejido adiposo, lo cual genera confusión en los foros científicos. Los términos células estromales derivadas del tejido adiposo (Adipose Tissue-Derived Stromal Cell: ADSC), células de la fracción vascular de la grasa (Adipose Stromal-Vascular Cell Fraction: SVF) y células regeneradoras derivadas de la grasa (Adipose-Derived Regenerative Cells: ADRC) corresponden a células obtenidas inmediatamente después de la digestión del tejido adiposo por colagenasas; por el contrario, los términos células provenientes del lipoaspirado (Processed Lipoaspirate Cells: PLA) y células madre derivadas del tejido graso adherentes al plástico (Plastic-Adherent Adipose-Derived Stem Cells: ASCS) describen a aquellas CM obtenidas después de cultivar las anteriormente mencionadas. Como término unificador, podemos referirnos a estos tipos celulares como células madre derivadas del tejido adiposo (Adipose-Derived Stem Cells: ASC) de acuerdo con el Consenso de La Sociedad Internacional de la Tecnología Aplicada a la Grasa (International Fat Applied Technology Society Consensus) (Lasso et al., 2010; Salem y Thimermann, 2010; Macías-Abraham et al., 2010). En el año 2006, la Sociedad Internacional para la Terapia Celular (International Society for Cell Therapy: ISCT) propuso tres criterios mínimos para ser consideradas ASC: primero, estas células deben ser adherentes al plástico en condiciones 
estándar de cultivo; segundo, tener un fenotipo positivo ( $\geq 95 \%$ ): CD105, CD73, CD90, fenotipo negativo ( $\leq 2 \%)$ : CD45, CD34, CD14 o CD11b, CD79 $\alpha$ o CD19, y HLA-DR; y tercero, deben ser capaces de diferenciarse in vitro en osteoblastos, adipocitos, condroblastos bajo condiciones estándar de cultivo (Dominici et al., 2006; Da Silva, Caplan y Nardi, 2

\section{Objetivos}

El presente trabajo contribuirá a estandarizar protocolos para el autotransplante y práctica clínica, utilizando cultivo in vitro de células madre derivadas de tejido adiposo.

\section{Características de las MSC}

Se ha demostrado que las MSC de varios tejidos residen en un nicho perivascular y estas células han sido identificadas como pericitos (da Silva et al., 2008; Crisan et al., 2008; Corselli et al., 2010). Los pericitos no solo son células de soporte de la estructura vascular sino que también contribuyen a la estabilización de los capilares, al mantenimiento de su homeostasis y a la remodelación y maduración de los mismos. Esto establece al compartimiento perivascular como nicho de las MSC. Esta visión conecta a las MSC con el sistema vascular e inmunológico, como integrador fisiológico en los procesos de reparación/regeneración de los tejidos (Da Silva et al., 2008).

Entre las características más importantes de las MSC están las siguientes:
- Es multipotente (capacidad de diferenciarse en varios linajes): adipocito, osteoblasto, condrocitos, tenocitos, miocitos, células mesodermo visceral. Posible diferenciación de células de origen endodérmico y ectodérmico (hepatocitos, neuronas y cardiomicitos). Multipotencia aplicada a la regeneración y reparación de tejidos (Caplan y Dennis, 2006; Da Silva et al., 2008; Bertassoli et al., 2013).

- Propiedades de inmuno-modulación (inmunosupresoras y antiinflamatorias). Las MSC afectan profundamente la respuesta inmune a través de sus interacciones con los componentes del sistema inmune innato (NK "Natural Killer Cells") y adaptativo (DC "Dendritic Cells", Linfocitos T y B). Los productos secretados por las MSC en el sitio de la injuria reprime fuertemente la vigilancia inmunológica, inhibiendo el daño mediado por las células T y B en el sitio de la injuria. Esta inmunoprotección sirve para proteger al tejido de la pérdida de su "tolerancia" eliminando los problemas de autoinmunidad (Da Silva et al., 2008; Castro-Marreza et al., 2015).

- Capacidad de migrar hacia el sitio de las injurias o tumores, también denominado efecto paracrino. El uso de MSC para terapia celular es posible, ellos pueden injertarse sistemáticamente mediante inyecciones in vivo, así como exhibir una gran capacidad intrínseca de dirigirse al sitio de la injuria (Devine et al., 2003; Da Silva et al., 2008). 
Las MSC tienen la capacidad de reemplazar células y tejidos dañados afectados de manera congénita, por enfermedad degenerativa o mediante trauma. En tales procedimientos las MSC son administradas a los pacientes a través de la sangre o directamente en el tejido dañado. El uso de la terapia celular con MSC es actualmente tópico de debate; sin embargo, debido a sus tres propiedades biológicas; alta diferenciación, tropismo y capacidad inmunorreguladora. Las MSC son candidatas potenciales en terapia celular aplicable a muchas enfermedades, tales como enfermedad del injerto contra el huésped, enfermedades cardiovasculares y del cartílago, enfermedades autoinmunes; diabetes tipo I, artritis reumatoidea, esclerosis múltiple, lupus eritomatoso sistémico, etcétera (CastroMarreza et al., 2015).

Por otro lado, durante los últimos años, en el campo de la cirugía plástica y reconstructiva, se vienen desarrollando avances tecnológicos y quirúrgicos que abren la puerta hacia la utilización de tejidos generados artificialmente, con el fin de reparar zonas dañadas de la anatomía, sin tener que recurrir a donantes de tejido. Las MSC obtenidas del tejido adiposo han sido denominadas células madre derivadas del tejido adiposo (AdiposeDerived Stem Cells: ASC), y para que sea aplicada en medicina regenerativa debe reunir las siguientes características: encontrarse en gran cantidad (millones a miles de millones de células); extraerse mediante procedimientos sencillos; diferenciarse en múltiples líneas celulares de una forma regulada y reproducible; poder ser trasplantadas de manera sencilla y eficaz en un huésped autólogo y alogénico y, finalmente, ser manufacturada de acuerdo a los requisitos de la Good Manufacturing Practice (Lasso et al., 2010).

\section{AisLAMIENTO Y EXPANSIÓN DE MSC}

\section{Materiales}

- Buffer estéril X phospho-buffered saline (PBS).

- Solución estéril de 0,075 - 0,1 \% colagenasa tipo IA (de Clostridium histolyticum).

- Medio de cultivo control estéril (CM) (Dulbecco's Modified Eagle's Medium: DMEM) (4,5 g/L glucosa, L-glutamina), $50 \mathrm{ml}$ fetal bovine serum (inactivado por calor), $5 \mathrm{~mL}$ penicilina/estreptomicina $\quad \begin{array}{ll}10 & 000\end{array}$ IU penicilina, $10000 \mu \mathrm{g} / \mathrm{mL}$ estreptomicina). Como una opción, $5 \mathrm{ml}$ anfotericina B $(250 \mu \mathrm{g} / \mathrm{mL}$ anfotericina B) también puede ser añadido.

- Solución balanceada de Hank's, libre de $\mathrm{Ca}+2 \mathrm{y} \mathrm{Mg}+2$, con $10 \mathrm{mM}$ HEPES $\mathrm{Ca}+2$ y $\mathrm{Mg}+2$-Free-Hank's Balanced Salt Solution (CMF-HB-HBSS).

\section{Disgregación enzimática del tejido adiposo}

- La grasa humana será obtenida del proceso de liposucción, previa firma del consentimiento informado.

- Se llenará una tabla con las características del donador, el material graso será dispensado en tubos có- 
nicos de centrífuga de $50 \mathrm{~mL}$ (30 $\mathrm{mL}$ por tubo), los cuales contendrán $15 \mathrm{~mL}$ de solución balanceada de Hank's libre de $\mathrm{Ca}+2$ y $\mathrm{Mg}+2$ con $10 \mathrm{mM}$ HEPES $\mathrm{Ca}+2$ and $\mathrm{Mg}+2-$ Free-Hank's Balanced Salt Solution (CMF-HB-HBSS).

- El material será transferido a un frasco de polipropileno que contenga un volumen igual de una solución de Colagenasa I (500U) en PBS, e incubado a $37^{\circ} \mathrm{C}$ por $40 \mathrm{~min}$, en un baño de agua, agitar intermitentemente el frasco.

- Al final de la incubación, el contenido del frasco será transferido a tubos cónicos de $50 \mathrm{~mL}$ y centrifugados a 250 g por $10 \mathrm{~min}$, a temperatura ambiente.

- El material sedimentado será resuspendido en $15 \mathrm{~mL}$ de una solución de lisis de glóbulos rojos [155 mM $\mathrm{NH} 4 \mathrm{Cl}, 10 \mathrm{mM} \mathrm{KHCO} 3,0.1 \mathrm{mM}$ EDTA, $1 \mathrm{mM}$ piruvato de sodio, y 50 $\mathrm{U} / \mathrm{mL}$ deoxyribonuclease I (DNase I) en agua ultrapura] por $10 \mathrm{~min}$.

- Luego, los tubos serán llenados con RPMI-1640, que contengan $10 \%$ (v/v) FBS (RPMI/10) y centrifugado, el sobrenadante será descartado, y el pellet será resuspendido en RPMI/10 (lavado). Centrifugar y resuspender el pellet en RPMI/10. Contar en un hematocitómetro las células viables, que serán observadas por microscopía utilizando azul de tripán.

\section{Aislamiento y expansión de MSC}

- Después de disgregación enzimática, 1 x 10E6 células viables serán colocadas en places Petri de 100-mm (aprox. 15000 cells $/ \mathrm{cm}^{2}$ ) en $7 \mathrm{~mL}$ de medio Dulbecco's Modified Eagle's Medium (DMEM) que contenga 10\% $(\mathrm{v} / \mathrm{v})$ de suero fetal bovino (FBS) (DMEM/10), $1 \%$ de Fungizone (Life Technologies), y $1 \%$ de penicilina/ estreptomicina.

- El medio DMEM contendrá 2,2 $\mathrm{g} / \mathrm{L}$ de bicarbonato de sodio y $2,6 \mathrm{~g} / \mathrm{L}$ de HEPES, para ser incubado a $37{ }^{\circ} \mathrm{C}$ con $5 \%$ de $\mathrm{CO} 2$.

- Las células serán incubadas a estas condiciones por tres días; las células no adheridas serán removidas con el cambio de medio dos veces por semana.

- Cuando el cultivo alcance una confluencia del $90 \%$, el medio será removido, las células serán estabilizadas con una solución de CMF-HB-HBSS que contenga $1 \mathrm{mM}$ de piruvato de sodio y 0,5 de $\mathrm{mM}$ EDTA, incubado por $1 \mathrm{~min}$. Luego, las células serán despegadas con una solución CMF-HB-HBSS que contenga $0,025 \%$ de tripsina, e incubado a $37^{\circ} \mathrm{C}$ por $5-10 \mathrm{~min}$.

- La suspensión celular será removida de la placa, mezclada con igual volumen de RPMI/10, sera centrifugado y resuspendida en DMEM/10.

- Las células serán colocadas a una densidad de 250000 células viables 
por $100 \mathrm{~mm}$ placa (aprox. 3500 células $/ \mathrm{cm}^{2}$ ) en $7 \mathrm{~mL}$ de DMEM/10.

- Los pasajes siguientes se realizarán de la misma manera. Al final del segundo paso, se analizarán las células mediante citometría de flujo y
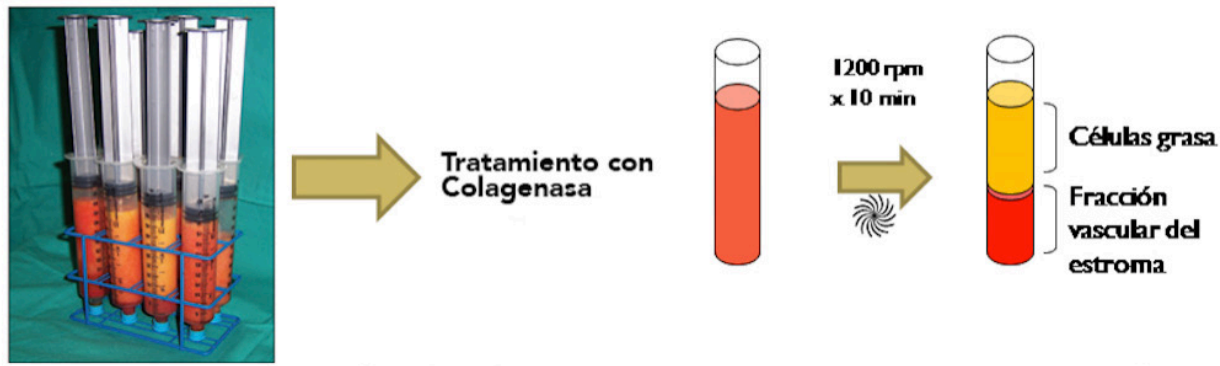
utilizada para la recolección de células será del 0,25\%, en lugar del 0,02 5\% (Da Silva Meirelles et al., 2015).

se preservarán en $\mathrm{FBS}$, conteniendo dimetilsulfoxido $10 \%$ (v/v). En estos casos, la concentración de tripsina

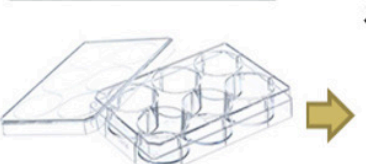

$3,8 \mathrm{~cm}^{2}$

$10^{\circ}$ pasaje

$2 .^{\circ}$ pasaje

3. ${ }^{\circ}$ pasaje

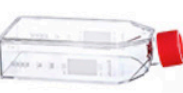

$25 \mathrm{~cm}^{2}$

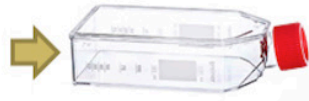

$2 \times 75 \mathrm{~cm}^{2}$

$8 \times 75 \mathrm{~cm}^{2}$

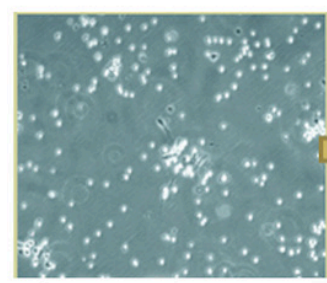

Fracción del estroma

$10 \%$ confluencia

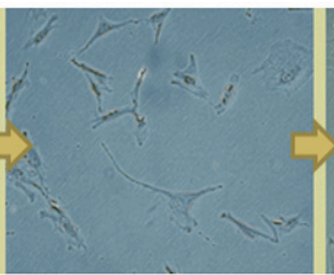

Figura 1. Proceso, aislamiento y expansión de MSC

La investigación de células madre es uno de los campos de mayor actividad e importancia y abre las puertas para notables progresos en el campo de la medicina, no solo de aquella que tiene que ver con enfermedades corporales sino también con la comprensión y eventual tratamiento de trastornos psicológicos. Como se sabe, los trastornos psicológicos son abordados fundamentalmente por procedimientos psicoterapéuticos y farmacológicos. No parece exagerado suponer que, en las próximas décadas (o tal vez antes), los resultados de la investigación de células madre puedan ser de utilidad y eventual empleo por parte de psicólogos, psiquiatras y neurólogos, lo cual significaría un progreso sustantivo en el tratamiento de dichos trastornos. 


\section{ReFERENCIAS}

Caplan, A. I. y Dennis, J. E. (2006). Mesenchymal stem cells as trophic mediators. Journal of Cellular Biochemistry, 98(5): 1076-1084.

Castro-Manrreza, M. E. y Montesinos, J. J. (2015). Immunoregulation by mesenchymal stem cells: biological aspects and clinical applications. Journal of Immunology Research. DOI: 10.1155/2015/394917.

Corselli, M., Chen, C. W., Crisan, M., Lazzari, L. y Péault, B. (2010). Perivascular ancestors of adult multipotent stem cells. Arteriosclerosis, Thrombosis and Vascular Biology. 30(6): 1104-1109.

Crisan, M., Yap, S., Casteilla, L., Chen, C. W., Corselli, M., Park, T. S., Andriolo, G., Sun, B., Zheng, B., Zhang, L., Norotte, C., Teng, P. N., Traas, J., Schugar, R., Deasy, B. M., Badylak, S., Buhring, H. J., Giacobino, J. P., Lazzari, L., Huard, J., Péault, B. (2008). A perivascular origin for mesenchymal stem cells in multiple human organs. Cell Stem Cell, 11(3): 301-313.

Da Silva Meirelles, L., Caplan, A. I. y Nardi, N. B. (2008). In search of the in vivo identity of mesenchymal stem cells. Stem Cells, 26(9): 2287-2299.

Da Silva Meirelles, L., Malta, T. M., De Deus Wagatsuma, V. M., Palma, P. V., Aráujo, A. G., Ribeiro, Malmegrim, K. C., Morato de Oliveira, F., Panepucci, R. A., Silva, W. A. Jr., Kashima Haddad, S. y Covas, D. T. (2015). Cultured Human Adipose Tissue Pericytes and Mesenchymal Stromal Cells Display a Very Similar Gene Expression Profile. Stem Cells and Development, 24(23): 2822-2840.

De Girolamo, L., Lucarelli, E., Alessandri, G., Avanzini, M. A., Bernardo, M. E., Biagi, E., Brini, A. T., D’Amico, G., Fagioli, F., Ferrero, I., Locatelli, F., Maccario, R., Marazzi, M., Parolini, O., Pessina, A. y Torre, M. L. (2013). Italian Mesenchymal Stem Cell Group. Mesenchymal stem/stromal cells. 2013. A new "cells as drugs" paradigm. Efficacy and critical aspects in cell therapy. Current Pharmaceutical Design. 19(13): 2459-2473.

Devine, S. M., Adkins, D. R. y Khoury, H. (2003). Recent advances in allogeneic hematopoietic stem-cell transplantation. Journal of Laboratory and Clinical Medicine, 141(1): 7-32.

Dominici, M., Le Blanc, K.; Mueller, I., Slaper-Cortenbach, I., Marini, F., Krause, D., Deans, R., Keating, A., Prockop, D. J. y Horwitz, E. (2006). Minimal criteria for defining multipotent mesenchymal stromal cells. The International Society for Cellular Therapy position statement. Cytotherapy, 8(4): 315-317.

Lasso, J. M., Cortina, E., Goñi, E., Arenas, L., Nava, P., Fernández, M. E. y Pérez Cano, R. (2010). Estado actual de las terapias con células madre derivadas de tejido adiposo en el ámbito de la Cirugía Plástica. Cirugía Plástica Iberolatinoamericana, 36(3): 215-221. 
Machado Bertassoli, B., Chaves de Assis Neto, A., Delys de Oliveira, F., Machado Arroyo, M. A., Pires Ferrão, J. S., Barbosa Da Silva, J., Pignatari, G. C. y Beltrão Braga, P. (2013). Mesenchymal Stem Cells - Emphasis in Adipose Tissue. Brazilian Archives of Biology and Technology, 56(4): 607-617.

Macías-Abraham, C., Del Valle-Pérez, L., Hernández-Ramírez, P. y Ballester-Santovenia, J. M. (2010). Características fenotípicas y funcionales de las células madre mesenquimales y endoteliales. Revista Cubana de Hematología, Inmunología y Hemoterapia, 26(4): 256-275.

Ra, J. C., Shin, I. S., Kim, S. H., Kang, S. K., Kang, B. C., Lee, H. Y., Kim, Y. J., Jo, J. Y., Yoon, E. J., Choi, H. J. y Kwon, E. (2011). Safety of intravenous infusion of human adipose tissue-derived mesenchymal stem cells in animals and humans. Stem Cells Development, 20(8): 1297-1308.

Rastegar, F., Shenaq, D., Huang, J., Zhang, W. y Zhang, B. Q. (2010). Mesenchymal stem cells: Molecular characteristics and clinical applications. World Journal of Stem Cells, 2(4): 67-80.

Salem, H. K. y Thiemermann, C. (2010). Mesenchymal stromal cells: current understanding and clinical status. Stem Cells, 28(3), 585-596.

Zuk, P. A., Zhu, M., Ashjian, P., De Ugarte, D. A., Huang, J. I., Mizuno, H., Alfonso, Z. C., Fraser, J. K., Benhaim, P. y Hedrick, M. H. (2002). Human adipose tissue is a source of multipotent stem cells. Molecular Biology of the Cell, 13(12): 4279-4295.

Zuk, P. A. (2010). The adipose-derived stem cell: looking back and looking ahead. Molecular Biology of the Cell, 21(11): 1783-1787. 